\title{
Exploring Immigrant Identities: The Link between Portuguese Ceramics and Sephardic Immigrants in $17^{\text {th }}$ Century Amsterdam.
}

\author{
Marijn Stolk
}

University of Amsterdam

\begin{abstract}
During urban expansions around 1600 a new neighborhood, Vlooienburg, was created in the rapidly growing city of Amsterdam. This new district was not just inhabited by local people, but also by immigrants coming from different European countries. Among those immigrants there were Sephardic Jewish people, who had fled from the Iberian Peninsula due to the persecution perpetrated by the Spanish Inquisition. By studying the archaeological finds that have been recovered from cesspits at Vlooienburg, an attempt is made to gain more knowledge about the composition of different cultural, religious and social identities living together in this area. As a part of the study of the material culture from Vlooienburg, this paper will present a case study that explores the possible relationships between the mobility of Portuguese ceramics and the presence of Portuguese immigrants. The paper will examine the distribution of different Portuguese wares to establish whether there were significant differences in how these ceramics were acquired and used within seventeenth century households in Amsterdam. The main result of this study is the remarkable link between Portuguese coarse cooking wares and the presence of immigrant households.
\end{abstract}

Keywords: Identity, Immigration, Ceramics, Urban Archaeology, Portuguese Faience and Red Wares.

\section{Introduction}

In 1981 and 1982, excavations in the Waterlooplein area of Amsterdam uncovered remains from the former historic district of Vlooienburg (Fig. 1). The excavations were undertaken by the Archaeology Bureau of the Amsterdam Department of Public Works, in advance of the redevelopment of the area. The work took place in two phases, exposing two of the originally four housing blocks from the district of Vlooienburg (Baart 1987 a). The excavation revealed up to 100 house plots, and in many cases also the cesspits corresponding to the original households dating from the early seventeenth century to the nineteenth century (Fig. 2). The significance of this discovery was further enhanced by the waterlogged nature of the deposits, which had resulted in excellent 
preservation of artifacts as well as organic materials. The cesspits had been used as latrines, but also contained dumps of households waste, yielding valuable assemblages of material culture and food remains (Gawronski et al. 2016; Baart 2001). In the early 1980s archaeological excavations in the Netherlands generally paid very little attention to early modern deposits. The Waterlooplein investigations may, therefore, be upheld as being highly progressive, and in many ways, ahead of their time. Unfortunately, resources were not available in the 1980s for an in-depth study of the finds, and therefore the assemblages remained - for the most part unpublished - in the City of Amsterdam's storage depot for more than 30 years. Recently, the department of Monuments and Archaeology (MenA) started processing the finds in preparation of the current research project Diaspora and Identity, for which funding is provided by the Dutch organization of Scientific Research (NWO). As a part of the Diaspora and Identity project led by the University of Amsterdam and the City of Amsterdam, the material culture recovered from the cesspits is now being used as primary evidence to study the identity of Vlooienburg's inhabitants. The wider aim of the project is to take an interdisciplinary approach that couples the data retrieved from the study of the material culture with the zoological and botanical remains, as well as the historical sources, in order to develop a truly holistic analysis of the evidence. We believe that recent developments in historical archaeology - in particular, the focus on identity issues and the archaeology of historical households (Fogle et al. 2015) - will allow us to construct a research framework that offers a comprehensive insight into domestic life in Vlooienburg.

This paper will focus on one specific element of this research: the material culture. It is my aim to establish whether or not it is possible to make a correlation between certain types of low status ceramic with the cultural and ethnic groups who lived in the neighborhood. The evidence that I will present is derived from a preliminary pilot study that I have conducted on selected pottery assemblages from the Vlooienburg as part of my $\mathrm{PhD}$ research. On a theoretical level, the ultimate goal of this study is to contribute to discussions about material culture and social identities. In particular, I seek to understand if household artifacts can be studied to provide evidence of social, economic and cultural processes, and to deepen understandings of adaptation, (forced) migration, and human attachment to things.

\section{Historical Background}

At the beginning of the 1600s, waves of 'Portuguese' immigrants arrived in Amsterdam, having fled the Iberian Peninsula, to escape being persecuted by the Portuguese and Spanish Inquisition. Due to the multiple waves of migration the often named 'Portuguese' immigrants who came to Amsterdam, did not necessarily come directly from Portugal. Though many of the immigrants were Portuguese in origin, it is known from historical sources that several of them had previously settled in Spain or Antwerp. In the previous century Spanish and Portuguese Jews had been forced to convert to Christianity, becoming so-called conversos. Nevertheless, some of them, the so-called crypto-Jews, continued to secretly practice Judaism. Some of the conversos and crypto-Jews were able to keep in touch with members of Jewish communities and maintained a 
certain level of Jewishness, whereas others felt it necessary to completely integrate with the Catholic lifestyle, for their own safety or for the sake of economic benefits. All in all the anti-Jewish measures led to problems in the formation of identities on a religious and social level and it thus was an important motive for migration. Since Amsterdam was considered to be a refuge with relative religious freedom and good economic potential, this was an ideal location for the conversos to settle and to restore their Jewishness, despite the fact that some of them had not been able to actually practice Judaism for a number of generations (Bodian 1997: 1-27; Levie 1987, 7-17; Stoutenbeek \& Vigeveno 2008: 15-16). Amsterdam and Holland were more or less tolerant towards Judaism, though the precise reason behind this tolerance is still point of discussion. It is generally appointed to the incidental economic benefits, though the tradition of the acceptance of minorities has to be taken in account as well. Jewish immigrants were allowed to become officially poorters (burghers) of the city of Amsterdam; however, this did not mean that they were allowed the exact same rights as other citizens. They were, for instance, excluded from guilds, which were organizing trades and crafts, and in contrast to Christian burghers, Jews could not become poorter by birth or marriage (Swetschinski 2000: 8-25).

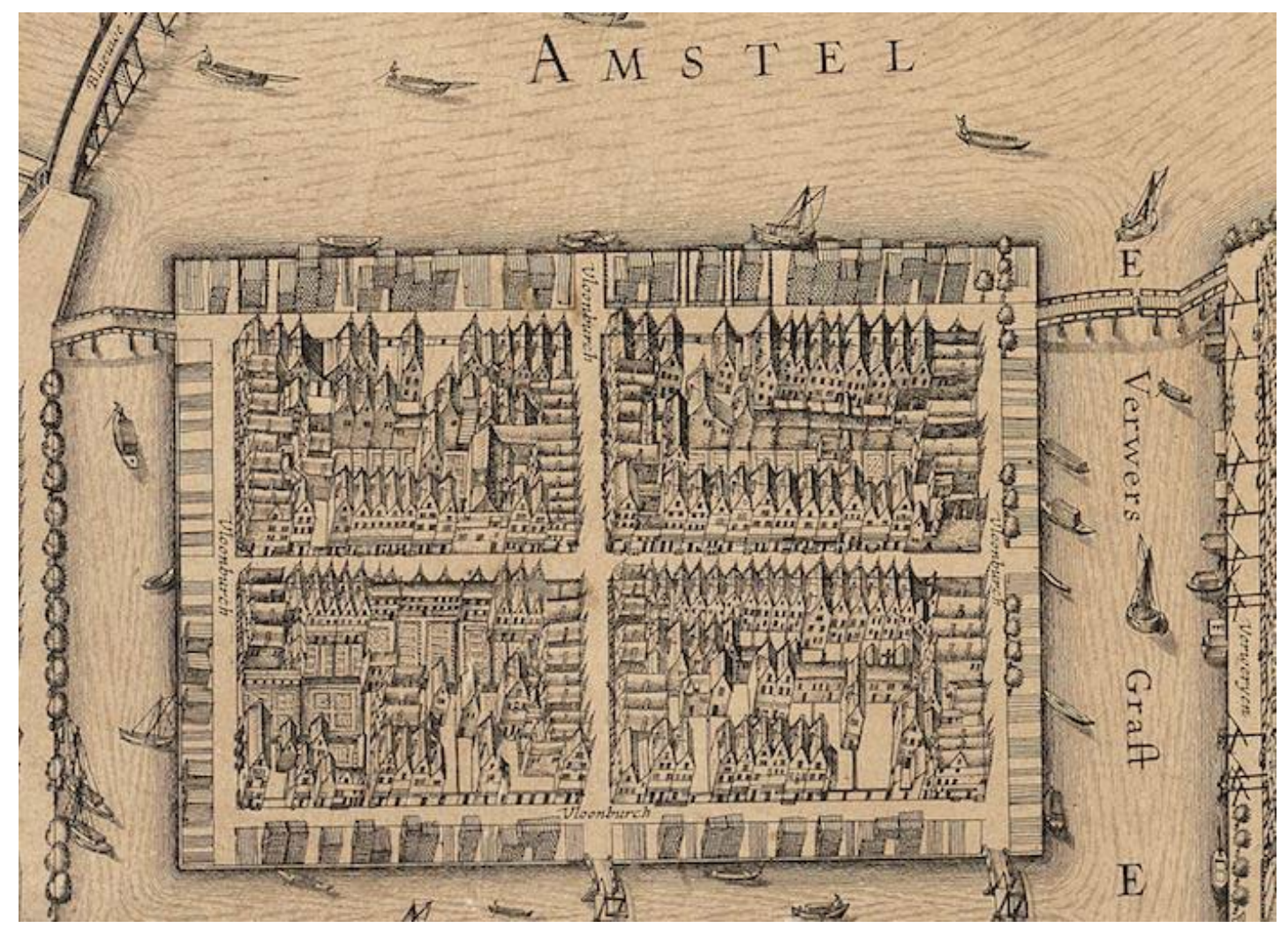

Figure1. Detail of the Vlooienburg district on the city map of Amsterdam, by Balthasar Florisz van Berckenrode, 1625 (Rijksmuseum Amsterdam, online collection, public domain: http://hdl.handle.net/10934/RM0001.COLLECT.335825)

During city expansions in Amsterdam between 1592 and 1595, four artificial islands were developed. The first three islands, Uilenburg, Marken en Rapenburg were primarily planned on account of shipbuilding and supportive activities. The town council decided upon the construction of the fourth island, Vlooienburg, in order to house incoming 
immigrants from the Southern Netherlands, due to the fall of Antwerp in 1585, and to take in immigrants from other parts of Europe (Gawronski et al. 2016: 38). Among Vlooienburg's first inhabitants were a considerable number of Jewish or conversos immigrants from the Iberian Peninsula. However, in contradiction to other European cities (such as sixteenth century Venice) there was no intentional separated ghetto for Jewish people in Amsterdam (Guidarelli 2016). Next to the Iberian immigrants, people of other origins resided in the same neighborhood, and over the course of the seventeenth century, Vlooienburg became a culturally mixed area, with immigrants coming from all parts of Europe (Kuijpers 2005; Municipal Archives of Amsterdam (GAA; Index Burgher Books 1531-1652). Nevertheless, the arrival of the Iberian immigrants at Vlooienburg marked the starting point for the development of the later called Jewish Quarter in Amsterdam. In the early seventeenth century, the first hidden synagogues appeared in Amsterdam and in 1639 the first openly Portuguese-Jewish Synagogue was built at the Houtgracht at Vlooienburg. From the mid-seventeenth century, Ashkenazi Jews also settled in the Vlooienburg district, joining the already established 'Portuguese Jewish community' (Stoutenbeek \& Vigeveno 2008: 76). The Ashkenazim had fled from Central and Eastern Europe as a consequence of the Thirty Years' War, the civil war in Poland, and the Russian invasion of Lithuania. Their main reasons for fleeing were rooted in the poor economic conditions and the anti-Jewish measures adopted by the Hapsburg and other regimes. By 1674, about 5,000 Ashkenazim had sought shelter in Amsterdam. In contrast with the immigration of Sephardim, which had more or less stabilized in the course of the seventeenth century, the immigration of Ashkenazim continued and by 1795 the number of Ashkenazi migrants in the city had grown to 22,000 (Wallet 2007).

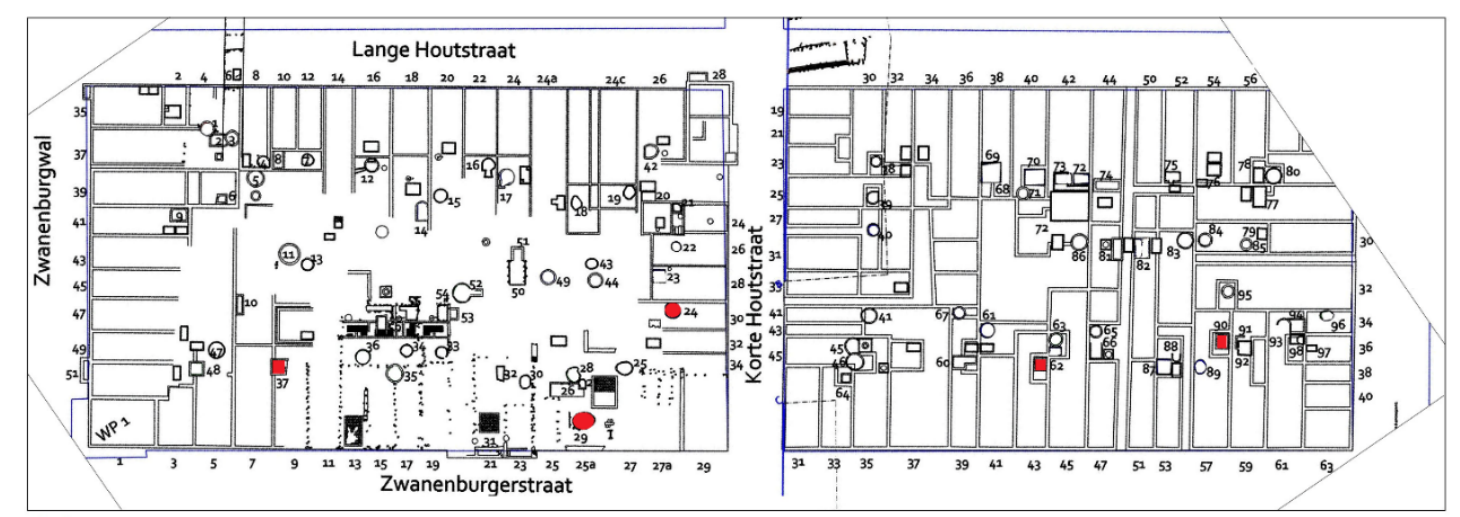

Figure 2. Overview of the excavated area of Vlooienburg, with the cesspits that are discussed in this article highlighted in red (Department of Monuments and Archaeology, City of Amsterdam).

However, it was not just war or religious persecution that drove migrants to Amsterdam; some people were drawn by the economic opportunities offered by the city. The work of Philip von Zesen, a seventeenth century German poet, depicts a very vivid picture of the lively business activities taking place at the Amsterdam Stock Exchange, described as a place where the whole world would trade and where one could encounter people from Poland, Hungary, Wallonia, France, Spain, Russia, Persia, Turkey and at times even from 
South Asia. The Portuguese immigrants, often originating from merchant families, took part in this trade market, bringing experience from the Portuguese colonial trade (Bodian 1997: 1). Taking all of the above into account, the Vlooienburg district can be considered an evident case study to investigate the mobility of Portuguese immigrants from an archaeological point of view.

\section{Theorizing (immigrant) identities and material culture}

The challenge of this research is to investigate whether the material culture that has been recovered from cesspits in Vlooienburg can be related to the historical events mentioned above, and to analyze to what extend the artefacts may have been used to maintain or to create new social identities by those living in the Vlooienburg neighborhood. This latter aspect is especially interesting when taking into account the fact that Vlooienburg was home to immigrants from different, ethnic, cultural and religious backgrounds, coming together in a city that played a leading role in the global maritime trading system at that time. A detailed interpretation in light of the shift in social and cultural elements in Amsterdam's seventeenth century society is presented by Schama (1988), who describes Amsterdam's process of transition from a modest place to a global trading center. Recent work sponsored by the City of Amsterdam underlines this image, presenting the rich variety of imported tablewares and other goods that became available to citizens after the formation of the Dutch East India Company, in 1602 (Gawronski 2012; Gawronski \& Kranendonk 2018).

Under the influence of the global trading network, we may well imagine indigenous Amsterdammers changing their dining routines and household possessions, acquiring exotic spices, high quality porcelains from the East, and tin-glazed wares from Italy and Spain. At the same time we might also expect non-local incomers to have been confronted with new material habits and faced with a choice to maintain their former lifestyles, or else to adjust to the local way of living, perhaps creating certain levels of hybridization.

An interest in investigating identity and ethnicity through the study of material culture is well present in the discipline already in the first half of the twentieth century. The most known examples are Gordon Childe's work from the 1920s, engaging the concept of (material) culture to groups of people, and Kossinna's work, considering the definition of regional ethnical groups based on unified sets of material culture or 'cultures' (Childe 1929; Kossinna 1928). These lines of research were often intertwined with the construction of contemporary identities, which, especially in Kossinna's work had political nationalistic undertones. After this period, most European archaeologists continued using comparable approaches that can be defined as culture-history approach, in which material culture was classified into groups that were implicitly regarded as the product of ethnically distinct communities. It was not until the advent of New Archaeology, and later the Processual Archaeology, that the focus gradually shifted. Culture was approached as a functioning system, rather than a homogenous normative framework of a specific group of people. Investigations of the interconnection between 
material culture distribution patterns and sets of events, showed how various possible processes could have led to similar models, making interpretations rather complex (Hodder \& Orton, 1976; Johnson 1999: 98-99). This resulted in new interpretative frameworks related to the analysis of economic strategies, exchange systems and social organization. Whereas in the past, material culture was used as a passive and illustrative tool, it became an object of study, being a source to study characteristics and fundaments of particular events, communities and societies at a given space and time (Prown 1982). In the last twenty years, socio-political investigations have been revived and have centered not only on ethnicity, but also on multiculturalism, setting conditions to explore archaeology as a contemporary practice, associated with the construction of cultural identity (Jones 1997: 1-10). The theoretical framework used to investigate the relationship between material culture and (ethnic) identity is therefore still in development. More recently, studies of identity in archaeological research have increased exponentially, leading to debates and criticism, on the one hand, due to what some archaeologists may regard as the straightforward relationship between material culture and identity, and on the other hand due to the lack of practical applicability of the concept identity in archaeology (see among others Jones 1997: 13-14; Parker 2013: 66$82)$.

A significant element concerning the interpretation of identity has more recently been described as the understanding of identity as a relational concept, in which light identity should be understood through the relations between people, objects and places, offering insight in the way in which people perceived and interacted with and related to the material world (Herva 2009; Harris \& Cipolla 2017). In a certain way, this is related to earlier theoretical approaches, such as Bourdieu's practical theory and concept of habitus, considering the dynamic reaction between people and the object world and vice versa, shaping and affecting each other (Bourdieu 1977). Earlier models and concepts were mainly based upon structured sets of rules and principles, which formed the basis of human action. These frameworks were characterized as dualistic structures, ones that did not take into account variability or cultural changes (Harris \& Cipolla 2017).

In recent studies, the contexts in which social consumption, cultural lifestyles and the creation of identities should be understood are described as social and cultural processes that include cultural mixing, rather than static sets of structured social and cultural values (Burmeister 2000; Woodward 2007; Parker 2013; Jervis 2014: 92-97). This approach is crucial when considering the different ethnic and religious identities that lived together in the district of Vlooienburg and when investigating to which degree the different cultures present assimilated or maintained and carried out their own customs. It can make us wonder how strict cultural boundaries and elements of identity were within the neighborhood and whether through time self-identifying groups may have mixed certain habits and practices. When exploring these cultural and social processes, it is important to take into account the variation in meaning and value of objects. Both the meaning and value of an object may differ according to context, whether it is a private or social setting, and its acting order, which might be functional or expressive (Harré 2002: 32). As is already described by Goffman (1956: 1-9), people tend to have a way of expressing 
themselves in social settings, intentionally or unintentionally; by sending out signals to impress others, to inform others about their cultural ideas or to sometimes maybe even to mislead others concerning the interpretation of their identity. Material culture plays a significant role in this system of social interaction and most certainly will have had an impact within an environment with different social, cultural and religious identities, such as Vlooienburg.

With his study on the probate inventories of French immigrants in early modern London, Parker, for example, argues that the expression of immigrant identities can be described in terms of complexity and diversity (Parker 2013). In the majority of the casestudies analyzed by Parker, there are no straightforward differences in domestic assemblages between immigrants and local inhabitants, although some specific artefacts could indeed be linked to non-local cultural identities. He also emphasizes the variation within material culture that may be detected when examining immigrants' households. For instance, one may find new styles and technologies co-existing besides objects that show a strong bond with traditional craft practices. This means that next to broader explanatory models, social structures and cultural processes, also individual preferences should be taken into account. Of course, Parker's research differs from this current case study, since probate inventories tend to mention the household items of higher economic value, whereas the archaeological finds from the cesspits reflect the rather accustomed items. Nevertheless, Parker contributes interesting insights into the connection between immigrant identities and specific (aspects of) artefacts.

\section{Research questions and Methodology}

At first sight it seems to be logical to associate the finds of Portuguese ceramics found at Vlooienburg with the Portuguese immigrants who fled to Amsterdam at that time, directly linking the movement of people with the movement of objects. However, the question remains whether this is a legitimate assumption. For, Portuguese ceramics were widely traded from at least the fifteenth century and have been found in several other cities along the North Western European coast, including places where there is no direct evidence for an influx of Portuguese migrants. Portuguese faience, the tin glazed eventually decorated with cobalt and/or manganese oxides, has been found, for instance, in a number of places in the Netherlands, such as Grootebroek, Zwaag, Dordrecht and Den Haag. It has also been discovered on several sites in Denmark and Sweden (Jaspers \& Ostkamp 2014; pers.comm. J. Linnaa; pers. comm. T. Wennberg).

In a first attempt to gain more insight on this matter, the complete ceramic assemblages of five cesspits ${ }^{1}$ from Vlooienburg, with a dating range between 1600 and 1775, have been studied in order to assess the overall share of Portuguese wares in comparison with the other ceramics. The cesspit assemblages have been recorded and categorized according to the Dutch standardized system, the so-called Deventer System. The

${ }^{1}$ Cesspits n. 24 (find n. 98), n. 29 (find n. 114), n. 37 (find nn. 138, 139, 140), n. 62 (find n. 234) and n. 90 (find nn. 300, 301). 
assemblages have been quantified through sherd count (n), by reconstructing the minimum number of vessels (MNV) and estimating the vessel equivalent (EVE). Characteristics like ware, shape, decoration, dimensions, have all been entered in a database system. Following the standards of the department of Monuments and Archaeology (MenA) of the City of Amsterdam, a distinction based on vessels' function has been made using the following categories (standard terms used by MenA): -table wares and food preparation wares; -cooking wares; -drinking wares; -storage and pouring wares; -ware for lighting and heating, and -wares for sanitation and care. During the analysis, the presence, composition, and function, of the different ceramic wares has been indicated and compared. In this way it is possible to assess to which category ceramics should be assigned and if the item had a practical or primarily decorative and expressive purpose. Following this first assessment, the data retrieved from this case study have been compared with previous research carried out on Portuguese ceramics in Amsterdam, the Netherlands and elsewhere Europe in order to establish the distribution and possible meanings and use of specific Portuguese wares.

As it turned out, the Portuguese faience from Amsterdam has been previously analyzed and quite extensively published, whereas the Portuguese coarse and red wares have been paid less thorough attention. For this reason a complete inventory has been made of all Portuguese ceramics from Vlooienburg, in order to place the items in a broader perspective, and to devise a realistic interpretation.

\section{Results}

The quantitative study of the five cesspits excavated at Vlooienburg is summarized in the column chart below (Fig. 3) showing frequency and compositions of the ceramic wares that were present per cesspit. What clearly stands out is that cesspit $\mathrm{n} .29$ contains a significant amount of Portuguese red and coarse wares (highlighted in pink as Iberian wares). This is in clear contrast to the other cesspits, which contained the wares that are generally expected in contemporary households in Amsterdam and elsewhere. These wares include: local red wares, white wares, local faience, local majolica, some stone ware and some porcelain. These latter results do not show too many deviations when compared with other contemporary cesspit assemblages (Gawronski \& Jayasena 2008; Gawronski, et al. 2012; Jaspers et al. 2015). The variation within cesspits from other locations in Amsterdam generally depends on time period and the social status of the owners. Notable within the Vlooienburg assemblages is the presence of imported faience in cesspits n. 29 (Portuguese and Italian) and n. 37 (French, Italian and Spanish), and of fragments of Danish Jydepotte in cesspit n. 90 and fragments of English industrial white and red wares in cesspit n. 62. 


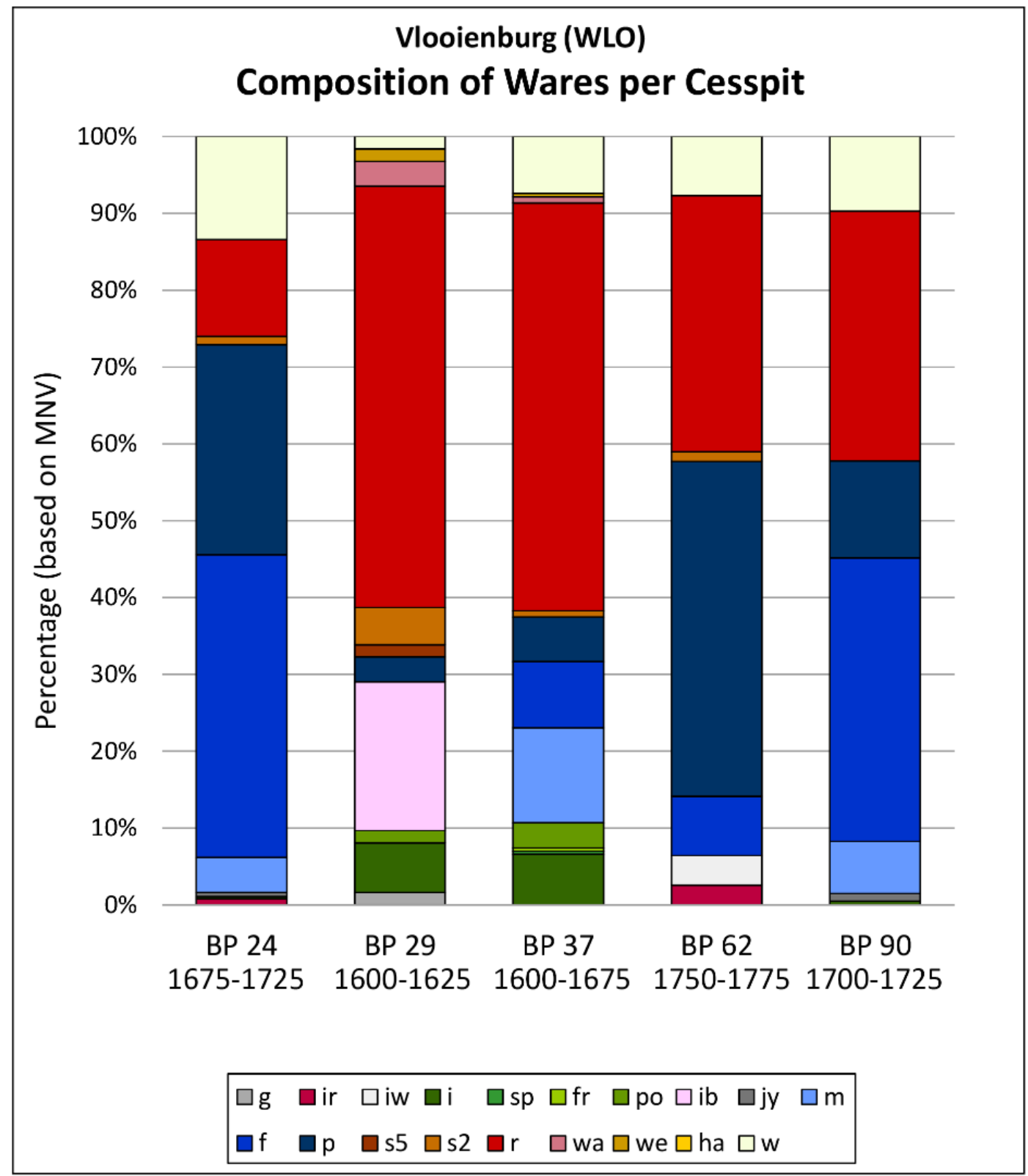

Figure 3. The composition of wares per cesspit, cesspit number and dating mentioned below column. Legend information according to the Deventer System: $\mathrm{g}=$ greyware, ir = industrial redware, $\mathrm{iw}=$ industrial whiteware, $\mathrm{i}=$ Italian faience, $\mathrm{sp}=$ Spanish faience, $\mathrm{fr}=$ French faience, po $=$ Portuguese faience, $\mathrm{ib}=$ Iberian wares, $\mathrm{jy}=$ Jydepotte, $\mathrm{m}=$ Dutch majolica, $\mathrm{f}=$ Dutch faience, $\mathrm{p}=$ porcelain, $\mathrm{s} 5=$ proto-stoneware, $\mathrm{s} 2=$ stoneware with glaze or engobe, $\mathrm{r}=$ redware, wa $=$ Werra ware, we $=$ Weser ware, ha $=$ Hafner ware, $\mathrm{w}=$ whiteware).

Cesspit n. 29 contained a total of 63 ceramic objects, 14 of which turned out to be of Portuguese origin. Considering the abundance of Portuguese ceramics in cesspit n. 29, a functional analysis has been carried out. This results in the column chart (Fig. 4), which shows that Portuguese red wares and coarse wares within the cesspit had been mainly used for the purpose of cooking, food preparation, dining, and storage. The term Portuguese red ware refers to the relatively thin walled ceramics than are mainly reddish or orange colored and tend to have a burnished or polished surface, sometimes decorated with patterned impressions. The term Portuguese coarse ware refers to the thicker walled ceramics with a rougher surface, although sometimes burnished as well and sometimes 
with clearly visible micaceous inclusions. In total, a minimum number of six bowls, three cooking pots, one frying pan, one storage pot and one amphora have been identified (see Fig. 5; nn. 1, 3, 4, 5 and 6, the storage pot and amphora are not illustrated). The cooking pot and frying pan can be compared with the Portuguese tacho and frigideira (Casimiro et al. 2017: 114 -115). Analyzed alongside these red and coarse wares were a plate and tiny bowl, possibly a salt cellar, in Portuguese faience were analyzed (see Fig. 5; n. 7 and n. 8). Taken together, these results indicate that this cesspit, which dates between circa 1600 and 1625, contained a considerable amount of Portuguese wares, varying in shape and function. It should be noted that the artifactual assemblage found in any given cesspit only represents a sample of the original set of objects that may have been used and discarded over time by a household. In addition to this the cleaning of cesspits at periodic intervals may have removed some dump deposits skewing the sample available for archaeological study (Van Oosten 2014). The high percentage of Portuguese wares in cesspit n. 29 at Vlooienburg nevertheless calls for closer reflection.

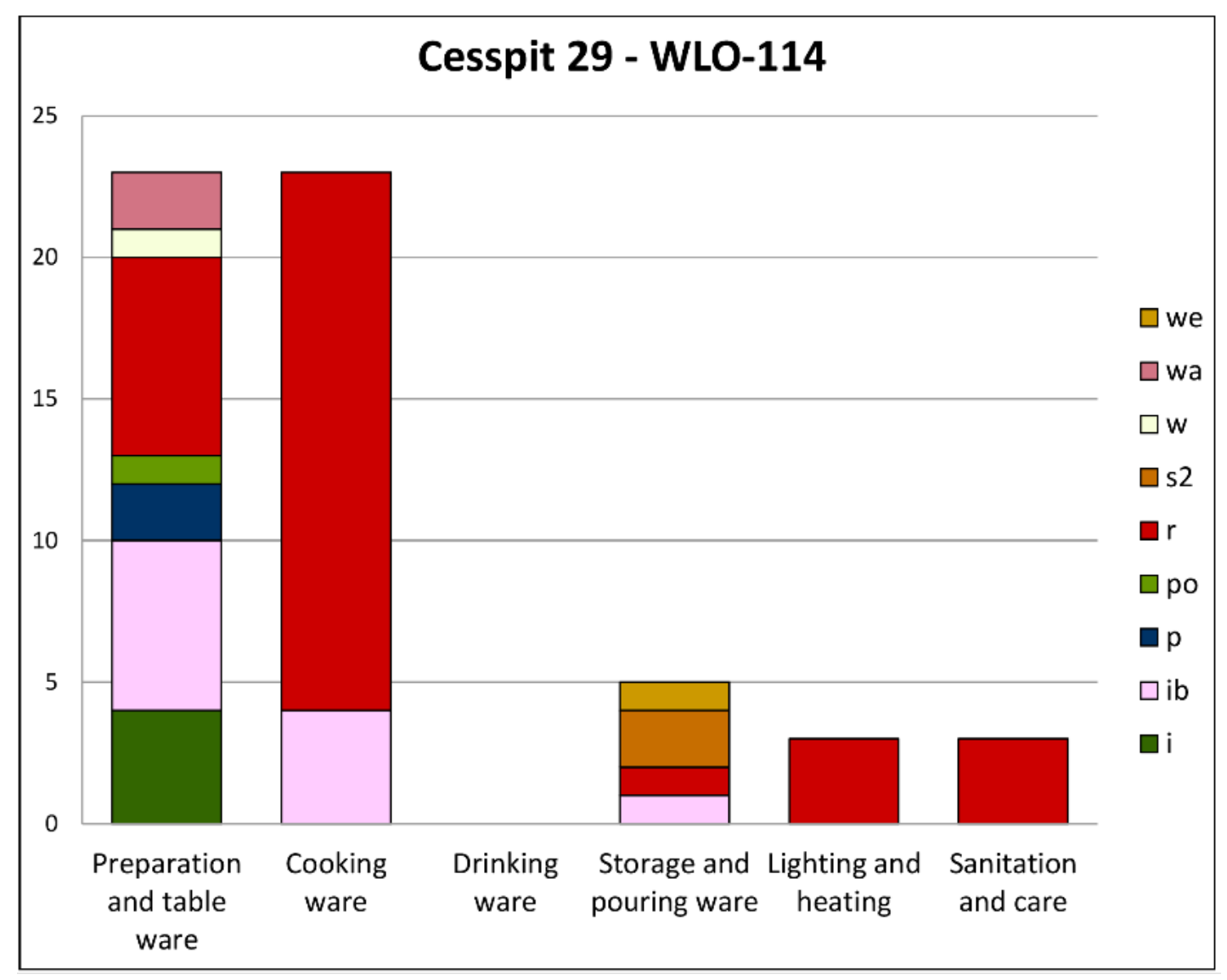

Figure 4. Overview of the ceramic wares grouped according to function for cesspit 29, showing in pink the Portuguese red and coarse wares and in bright green the Portuguese faience. Based on Minimum Number of Vessels. (Legend information according to the Deventer System: $\mathrm{i}=$ Italian faience, po = Portuguese faience, $\mathrm{ib}=$ Iberian wares, $\mathrm{p}=$ porcelain, $\mathrm{s} 2=$ stoneware with glaze or engobe, $\mathrm{r}=$ redware, $\mathrm{wa}=$ Werra ware, $\mathrm{we}=$ Weser ware, $\mathrm{w}=$ whiteware). 

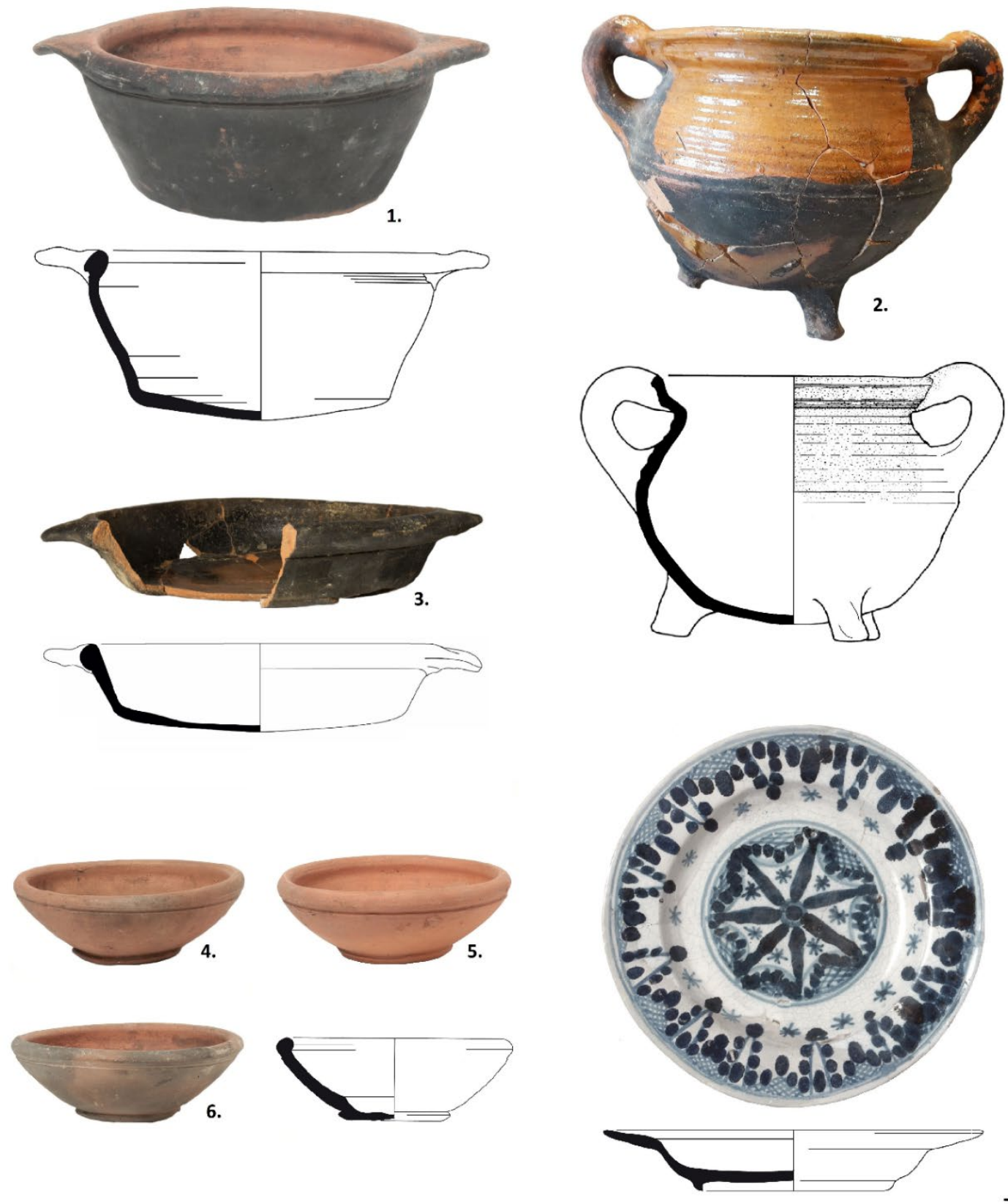

7.

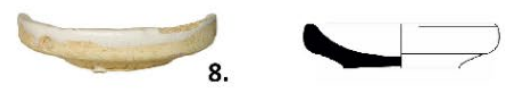

$5 \mathrm{~cm}$

Figure 5. Objects from Cesspit 29: 1. Portuguese cooking pot (WLO-114-6), 2. Dutch cooking pot (WLO114-29) 3. Portuguese frying pan (WLO-114-17), 4.-6. Portuguese bowls (WLO-114-2, WLO-114-3, WLO-114-5), 7. Portuguese faience plate (WLO-114-1), 8. Portuguese faience salt cellar (WLO-114-16). Pictures and drawings by R. Tousain, Department of Monuments and Archaeology, City of Amsterdam and author.

The most striking aspect of the data is the presence of two types of Portuguese cooking vessels within the ceramic assemblage. This significant as no other archaeological examples of such vessels have been previously reported in the Netherlands. Now that these items have been recognized it may be that more examples of Portuguese cooking 
vessels will be identified elsewhere. But I would suggest that the significance of these finds from Vlooienburg should not be understated. It is, for example remarkable that a scan of the complete Portuguese ceramics dataset from the city of Amsterdam showed no other examples from any other area within the city. Moreover, no examples of such Portuguese cooking vessels are attested anywhere else in the Netherlands so far. This raises the question: are these cooking wares possibly linked to the presence of Portuguese immigrants? In order to investigate such hypothesis, a brief survey of the occurrence of other Portuguese wares, as found in Amsterdam, the Netherlands and other parts of Europe, has been conducted to gain a better understanding of the possible context of these exceptional finds.

\section{Distribution, function and meaning of Portuguese ceramics}

\section{Portuguese faience}

Research published by Baart in the late 1980s and early 1990s had already established the fact that the Vlooienburg cesspits contained an abundance of Portuguese ceramics. However, these earlier studies have mainly focused on two specific classes: the Portuguese faience and what was then termed 'Portuguese terra sigillata', referring to the finely shaped and decorated red wares, that were possibly produced at Estremoz, Portugal (Baart 1987a, 1987b, 1992). In the first instance faience was primarily linked to the Portuguese Jewish inhabitants of Vlooienburg, especially since some of the ceramics carried names or coat-of-arms of Portuguese families. However, more recent work in the city has established that Portuguese faience is also found in other parts of Amsterdam and elsewhere in the Netherlands (Baart 1987a: 18-24). More importantly, its distribution over the course of the seventeenth century shows a clear pattern along the western coastal area. Faience, which became the more common table ware in Portugal in the course of the seventeenth century, is widely attested at harbour cities and hubs related to maritime trade, such as Amsterdam, Zaandam, Edam, Enkhuizen, Harlingen, Hoorn, Middelburg, Purmerend, Rotterdam, Vlissingen, Zwaag, Blokker, Grootebroek, Graft en de Rijp (Jaspers \& Ostkamp 2014: 16-17; Bartels 2003: 71-78). In addition, Portuguese faience is present in other European cities that were trading with Portugal. This can be observed for example in Scandinavia, England, and Ireland. And, even further afield faience has been routinely excavated in Portuguese colonies, such as Brazil, Cape Verde, Goa, Madeira and the Azores, as well as in Spanish and English colonies (Casimiro 2011, 2014a, 2014b).

The idea that I would like to advance here is that there are different explanations for the presence of faience in these various places. The finds from the Portuguese colonies do not come as a surprise, considering that the colonies were tied into trade with the motherland, and Portuguese settlers may have wanted to preserve and maintain a common lifestyle. A similar case can be found in the Spanish colonies (Deagan 2013). It is worth bearing in mind that back then Spain and Portugal had been united under the same crown for more than half a century. The presence of Portuguese faience in English 
colonies may be explained as an intentional choice to pursue a European lifestyle in the New World through the import of high-quality products from European countries. In the European countries, Portuguese faience is traditionally explained as result of a larger trading system, through which many other products, such as olive oil, wine, sugar and salt, were acquired. In Amsterdam and the Low Countries high-quality faience is mostly found in the domestic refuse of wealthier households. It can be said therefore that in some cases faience was put to a primarily functional use in daily activities, since this mainly contain table wares. Another interpretation is that sometimes very high quality faience might have been used as decorative household ornament rather than as table ware, representing a more expressive role (Casimiro 2014b).

\section{Portuguese red wares}

The earliest examples of Portuguese red wares in the Netherlands are the so-called "fancy Estremoz ware" (fine red ware), which have been uncovered from contexts associated with wealthy households. The finds recovered at the castle 'De Haar' at Culemborg, at Dordrecht, and in The Hague may be used to illustrate this point (Jaspers \& Ostkamp 2014: 15-16). The fine red wares were nicely decorated and were, outside of Portugal, considered luxury objects at their time. They were related to gift-exchangesystems among noble and elite societies in the sixteenth century, as it is shown by the example of King Philip II (1527-1598), who ordered Estremoz pottery as a gift for his daughters (Jaspers \& Ostkamp 2014: 11). It is usually argued that the wealthier citizens in the Low Countries followed such fashion in the seventeenth century. The fine red wares were more or less common in Portuguese households, as is illustrated by the many drinking cups found in contexts in Lisbon. The undecorated cups were found in general households, whereas the decorated version, so-called moldada wares, are only to be found in wealthy contexts (pers. comm. T. Casimiro). The fine red wares are found in approximately twenty households in Amsterdam. Within Vlooienburg, there is even a cesspit in which sixteen pieces were found. The Vlooienburg finds were mainly from beakers, cups, small bowls, jugs and bottles, with numerous variations in colour, decoration, inclusion and shape. Fragments of similar pieces have been also found in cities in the province of North-Holland that seem to be related to Portugal because of the salt-trade (Baart 1992: 273-278). Similar fine Portuguese red wares are known from the city of Antwerp, which was a very important hub in the trading network of Northern and Central Europe. Fine red wares have also been recovered from a high-status rural site in Flanders that was owned by a family member of an old Spanish-Portuguese noble family (Veeckman 1994; Poulain et al. 2017). It can thus be inferred that there are two main reasons for the appearance of the fine and delicate red Portuguese ceramics outside of Portugal. In the first instance, such ware was apparently a highly appreciated good amongst noble and elite societies. Later on, this fashion seems to have been adopted by the more prosperous citizens in cities that were part of Portugal's maritime trading network. A recent study shows that one possible explanation for the popularity of these fine red wares might lay in the particular smell and taste that some of the drinking cups would add to water, which increased the reputation of drinking from these 
special wares (Newstead \& Casimiro, in preparation).

\section{Portuguese coarse wares}

The household wares within the archaeological assemblages from Vlooienburg were briefly mentioned, but largely overlooked by earlier studies whereas the fancy ceramics, namely the faience and the fine red wares, were more intensively studied (Baart 1992). This may also be the case at comparable sites. Portuguese coarse wares, for example, have certainly been found in Antwerp, but they are only briefly described and are not illustrated in publications. This is in contrast to the fine red wares, which are given far more attention (Veeckman 1994: 17).

Portuguese coarse wares were used for various purposes, including: domestic use, industrial purposes and commercial reasons. Among the domestic vessels there are many types that were used for cooking, food preparation, and dining, but there are also examples of storage vessels and even chamber pots (Casimiro 2014a). The industrial objects consist of sugar cones and syrup pots and the commercial vessels are storage jars that were used as containers to transport different Portuguese commodities. Portuguese coarse wares are the most commonly used wares in Portuguese households, but are also found in many other countries across Europe and beyond, including: England, Ireland, Scotland, the Low Countries, Germany, Denmark, Canada, the USA, Brazil and African countries. Commercial and industrial coarse wares that are found outside of Portugal, are, for example, those found in Southampton, England (Gutierrez 2007) or those known from Newfoundland, Canada (Newstead 2013). Cooking wares, however, were not present at these sites. The only overseas example of Portuguese cooking vessels that is known comes from the site of Plymouth, were a numbers of cooking vessels have been found. The interpretation of these household-related coarse wares is that they might have belonged to a small Portuguese community living there during the early modern period (Newstead 2014). According to the historical ship logs (or official records), however, both the household wares and the containers for goods, such as amphoras, were to be transported (Casimiro 2014a). It seems plausible to suggest that the household wares were primarily transported for use by Portuguese settlers abroad, whereas the other goods were transported all over the different countries as prestige items.

As mentioned earlier, in Amsterdam Portuguese coarse wares that are specifically related to cooking and food preparation have only been found in the Vlooienburg neighborhood and are not known from any other excavation in the Netherlands. The inventory of the Portuguese ceramics from Vlooienburg showed that cooking and food preparation wares are present in at least twelve different cesspit contexts, from which the ones that are fully analyzed date between circa 1600 and 1650. In contradiction to the distribution of the coarse ware storage jars found in many other countries, the cooking wares that were found in Vlooienburg are only known from a few archaeological contexts other than the records in Portugal or Portuguese colonies (pers. 
comm. T. Casimiro). It may be argued therefore that these specific coarse wares brought to Amsterdam by the Portuguese settlers at the beginning of seventeenth century as part of their household assemblage. If this were indeed the case, then one might expect similar finds in Antwerp or Hamburg because of the Sephardic immigrants in those places. This should be considered for future research. Further work might also investigate whether these cooking wares are only present in the first half of the seventeenth century, or if they are also present in later contexts. This should be done in order to find out if the households maintained this use of Portuguese cooking wares or whether at a certain point they switched to using local cooking vessels. Perhaps the presence of Portuguese cooking utensils could have been related to cooking traditions or the preparation of specific Mediterranean or Jewish dishes. Considering the interdisciplinary aspect of the Diaspora and Identity project this is definitely an aspect that will be worked on in future research, with the assistance of scientific examination through residue analysis.

\section{Conclusions}

This preliminary foray into the ceramic assemblages of the Vlooienburg site, including only a small sample size, has already uncovered a fascinating Portuguese connection, demonstrating the necessity of further research. The Portuguese cooking wares seem to be a very rare set of finds and most likely can be directly related to the Sephardic immigrants who began to settle in Amsterdam from around the 1600s onwards. A first indication in favour of this hypothesis is the fact that these typical Portuguese cooking vessels, showing clear traces for use over open fire, are (so far) barely found in contexts outside of Portugal or Portuguese colonies, as is known so far (Casimiro 2014a). The single known example, in Plymouth, is related to a community of Portuguese settlers (Newstead 2014). Secondly the materials described in this article come from a cesspit dating between circa 1600 and 1625, which accords with the first generation of Sephardic Jews moving to Amsterdam. In addition to this, a survey of all Iberian wares found in Amsterdam, surprisingly showed that no comparable Portuguese cooking vessels have been found in any other district of Amsterdam. No similar finds have been made in the rest of the Netherlands and or Europe, with the obvious exception of Portugal itself. In contradiction to the Portuguese ceramics that took part in systems of trade or gift-exchange, it seems that the Portuguese cooking vessels played a much more private and personal role.

Placing this issue within a more theoretical framework, it is interesting to note, that apparently the Portuguese settlers maintained a Portuguese way of cooking and food preparation as an aspect of a traditional lifestyle. So, at least for the first period of time after their arrival in their new homes, they seem to have held on to at least part of their original identity. More research on the Vlooienburg cesspits will be carried out to investigate whether the Portuguese cooking wares are solely found in contexts dating to the period of migration, or if that they are also found in later contexts. For now, elements of a traditional lifestyle mainly seem to appear in material culture related to the private domain of the house, namely the kitchen. However, further research has to show 
if similar patterns could be detected in the material culture that is related to social contexts. Also at this stage of research the main topic of the investigation was to see whether Portuguese cooking traditions were preserved, but an interesting aspect that will be part of later analyses is the question: can Jewish practices also be detected, with regards to the Jewish food laws? According to the Jewish food laws the preparation and consumption of meat and dairy products should be kept separately, which in some case might have led to separated sets of kitchen and tablewares. Whether this could be visible in the ceramic assemblages of the Vlooienburg cesspits will be another topic of research within the Diaspora and Identity project. Organic residue analysis might also reveal if the Portuguese cooking vessels from Vlooienburg have been used for preparing specific sorts of dishes, as was the case with comparable cooking vessels, found during the excavation at Largo de Coreto, Carnide; Lisbon, Portugal (Casimiro et al. 2017). In any case, it will be interesting to further investigate the role of cooking wares in the process of maintaining old customs or adapting new habits in the lifestyles of immigrants that settled at Vlooienburg. Although not discussed in detail in this article, one of the five analyzed cesspits contained cooking ware with a Danish origin, the so-called Jydepotte, which might be an interesting future lead into the search for immigrant identities.

It is far more difficult to relate the example of Portuguese ceramics within the discussion to the ethnic backgrounds of immigrants. Could it be that is was the function, value and/or meaning of ceramics that played a significant role, rather than the provenance? It might also be the case that some of the coarse ware shapes were themselves of secondary importance, because they were simply used as a container for other commodities, while in other cases one single piece of fine and elegant red ware could be of high economic and social value and be of importance in the construction of networks among the elites in society. Besides the functional or sometimes rather symbolic character of the ceramics, the contexts in which they operated are of crucial importance. The cooking wares, low in economic value and used in the private domain of an immigrant's household, had a significantly different role than the (probably) expensive imported high-quality faience that was used as an expressive decorative element in the household of a local citizen. Additionally, it is needless to say that there probably are countless nuances within these contexts and, therefore, within the appreciation of an objects value and meaning. In order to incorporate these factors in future research, a more holistic concept, taking into account the assemblage of ceramics and other material culture present, might be useful to be included.

\section{Acknowledgements}

I would like to thank the Department of Monuments and Archaeology (MenA) from the City of Amsterdam for making it available to study all these materials and for their help with the interpretation of finds, with a special thanks to Jerzy Gawronski, Ranjith Jayasena and Ron Tousain. I am very grateful to Tânia Casimiro for her help with the determination of the Portuguese ceramics, for showing me similar finds in Lisbon and for (Portuguese) literature suggestions. Furthermore, I would like to thank Michiel 
Bartels, Maxime Poulain, Jette Linaa, Tom Wennberg, Johan Veeckman and Tim Bellens for thinking along about the eventual presence of Portuguese cooking wares in other collections within Europe. Finally, I would very much like to thank James Symonds, Martina Revello Lami and Lindsay Morehouse for their help and Ex Novo Journal of Archaeology for the opportunity to publish this article.

\section{References}

BAART, J., 1987a. Portugese faience 1600-1660 - Een studie van bodemvondsten en museumcollecties, in R. KistemaKer \& T. LEVIE (eds.). Exodo - Portugezen in Amsterdam 1600-1680. Amsterdam: Amsterdams Historisch Museum, De Bataafse Leeuw, 18-24.

BAART, J., 1987b. Portugese Faience uit Amsterdamse Bodem, in: C. van LAKERVELD \& T. Oliveira van Royen (eds.) Portugese Faience 1600-1660. Amsterdam - Lissabon, 1995.

BAArT, J., 1992. Terra Sigillata from Estremoz, Portugal, in: D. GAimster \& M. REDKNAP, Everyday and Exotic Pottery from Europe c 650-1900 - Studies in honour of John G. Hurst. Exeter: Oxbow books, 273-278.

BAART, J., 2001. Nieuwe inzichten in oude huishoudens. Jaarboek. Amstelodamum 93: 195209.

Bartels M. H., 2003. Cerâmica Portuguesa nos Países-Baixos, uma análise socialeconómica à base de material arceológico encontrado. Patrimonio Estudos (Instituto Portugues do Patrimonio Arquitectonico) 5: 70-82.

Bodian, M., 1997. Hebrews of the Portuguese Nation - conversos and community in early modern Amsterdam. Bloomington, Indianapolis: Indiana University Press.

Bourdieu, P., 1977. Outline of a Theory of Practice (Cambridge Studies in Social and Cultural Antropology, No. 16). Cambridge: Cambridge University Press.

Burmeister, S., 2000. Archaeology and Migration: Approaches to an Archaeological Proof of Migration. Current Anthropology, Vol. 41, No. 4, 539-567.

Casimiro, T.M., 2011. Portuguese faience in England and Ireland, Britisch Archaeological Reports (BAR) International Series 2301. Oxford: Archaeopress.

CAsimiro, T.M., 2014a. Portuguese Redwares and Coarse Wares in Historical Archaeology, in: C. SMITH (ed.), Encyclopedia of Global Archaeology. New York (NY): Springer,

6045-6051.

Casimiro, T.M., 2014b. Portuguese Faience and Historical Archaeology, in: C. SMith (ed.), Encyclopedia of Global Archaeology. New York (NY): Springer, 6037-6044.

CAsimiro, T.M., C. BoAvidA, C. \& C. DetRY, 2017. Cozinhar e comer: cerâmicas e alimentação em Carnide (1550-1650), in: J.C.S. Martínez, A.C. MARTins, A.Á.D. Melo, A. Caessa, A. Marques \& I. Cameira (eds.), Diz-me o que comes... Alimentação Antes e Depois da Cidade. vol. 1, Lisboa, 110-121.

ChILDE, V., 1929. The Danube in Prehistory, Oxford: Oxford University Press.

Deagan, K., 2013. Hybridity, Identity and Archaeologicl Practice, in: J. JeB (ed.), The Archaeology of Hybrid Material Culture, Card. Center for Archaeological Investigations, Occasional Paper No. 39, Illinois (IL): Southern Illinois University. 
Fogle, K.R., J.A. Nyman \& M. C. BeAudry, 2015. Beyond the Walls: New perspectives on the Archaeology of Historical Households, University Press of Florida.

GAWRONSKI, J. \& R. JAYASENA, 2011. Wonen achter de Ouderijds Voorburgwal, Archaeologische Opgraving Oudezijds Armsteeg, Amsterdam (2008), AAR 60. Amsterdam: Gemeente Amsterdam, Bureau Monumenten en Archeologie.

Gawronski, J., 2012. Amsterdam Ceramics: A city's history and an archaeological ceramics catalogue 1175-2011. Amsterdam: Uitgeverij Bas Lubberhuizen / Bureau Monumenten en Archeologie.

Gawronski, J., R. Jayasena \& J. Veerkamp, 2012. 'Ons Genoegen', Archeologische Opgraving Elandsstraat 101, Amsterdam (2010), AAR 67. Amsterdam: Gemeente Amsterdam, Bureau Monumenten en Archeologie.

GaWronski, J., R. JayAsena \& S. IJZERman, 2016. De gelaagde stad onder het Waterlooplein. Jaarboek. Amstelodamum 103-I: 38-47.

GAWronski, J. \& P. KranendonK, 2018. Stuff: Catalogue of Archaeological Finds from Amsterdam's North/South Metro Line. Amsterdam: Uitgeverij De Harmonie.

Goffman, E., 1956. The Presentation of Self in Everyday Life, University of Edinburgh, Social Science Research Centre, Monograph 2.

Guidarelli, G., 2016. Cosmopolitan Venice, in: D. Calabi (ed.) Venice, the Jews and Europe: 1516-2016. Venezia: Marsilio, 94-97.

GUTIÉRREZ, A., 2007. Portuguese coarsewares in early modern England: reflections on an exceptional pottery assemblage from Southampton. Post-Medieval Archaeology 41:1: 6479.

Harré, O.J.T., 2002. Material Objects in Social Worlds (Theory Culture and Society, 19). Sage Publications.

Harris, O.J.T. \& C. Cipolla, 2017. Archaeological Theory in the New Millennium: Introducing Current Perspectives. London: Routledge.

HERVA, V.P., 2009. Living (with) things: relational ontology and material culture in early modern northern Finland. Cambridge Archaeological Journal, 19(3): 388-397.

Hodder, I \& C. OrTon, 1976. Spatial Analysis in Archaeology. Cambridge: Cambridge University Press.

Jaspers N.L. \& S. OstKamp, 2014. Portugese faience uit Nederlandse bodem. De opkomst en neergang van Portugese import. Vormen uit Vuur 226 (2014/3): 10-29. JASPERS N.L., Y. EIJSKOOT \& E. EsSER (eds.), 2015. Runve bolsters, bierdrinkers en haringeters: Huishoudelijk afval van de eigenaren, bewoners en ambachtslieden van de scheepswerf aan de Havenstraat in Vlaardingen (locatie Galeiwerf), Amsterdam: Terra Cotta Incognita, Special, nr 2.

Jervis, B, 2014. Pottery and Social Life in Medieval England, Oxbow books, Oxford, 92-97. Johnson, M., 1999. Archaeological Theory: An Introduction. Oxford: Blackwell Publishing. JONES, S., 1997. The Archaeology of Ethnicity: Constructing identities in the past and present. London: Routledge.

KossinNA, G., 1928. Ursprung und Verbreitung der Germanen in vor-und frübgeschicbtlicher Zeit. Lipsia: Kabitzsch.

KUJjPERS, E., 2005. Migrantenstad - Immigratie en sociale verhoudingen in $17^{\circ}$ eeuns Amsterdam, Hilversum: Uitgeverij Verloren.

Levie, T., 1987. Marranen in de zeventiende eeuw, in: R. KIsTEMAKER \& T. LEVIE, 
Exodo - Portugezen in Amsterdam 1600-1680. Amsterdam: Amsterdams Historisch Museum/De Bataafse Leeuw, 7-17.

Newstead, S., 2013. Merida no More: Portuguese Redware from Newfoundland, in: P.E. Pope \& S. LeWIS-Simson (eds.), Exploring Atlantic Transitions: Archaeologies of Transience and Permanence in New Found Lands, Society for Post-Medieval Archaeology, Monograph 8. Rochester, Boydell \& Brewer, 140-151.

Newstead, S., 2014. Cod, Salt and Wine: Tracing Portuguese Pottery in the English North Atlantic World. North Atlantic Archaeology 3: 75-92.

Newstead, S. \& T. CASImiro (in preparation). What's that Smell: New directions for Material Studies.

Parker, G., 2013. Complexity and diversity: domestic material culture and French identity in early modern London. Post-Medieval Archaeology 47.1: 66-82.

Poulain, M., J. van Vaerenbergh \& W. De ClercQ, 2017. A Portuguese lifestyle in the Flemish countryside: ceramics of the Ximenez family (1595- c. 1700). Post-Medieval Archaeology 51.2: 274-308.

Prown, J.D., 1982. Mind in Matter: An Introduction to Material Culture Theory and Method. Winterthur Portfolio 17.1:1-19.

Schama, S., 1988. The Embarrassment of Riches: An Interpretation of Dutch Culture in the Golden Age. London: Fontana Press.

Stoutenbeek, J. \& P. Vigeveno, 2008. Joods Amsterdam. Zutphen: KM Publishers. SwetsChinsKI, D.M., 2000. Reluctant Cosmopolitans: The Portuguese Jews of Seventeenth-Century Amsterdam. The Littman Library of Jewish Civilization.

Veeckman, J., 1994. Iberian Unglazed Pottery from Antwerp (Belgium), Medieval Ceramics. Journal of Medieval Pottery Research Group 18: 9-18.

VAN OOSTEN, R., 2014. De stad, het vuil en de beerput: Een archeologisch-historische studie naar de opkomst, verbreiding en neergang van de beerput in stedelijke context $\left(13^{\text {de }}\right.$ tot $18^{\text {de }}$ eeuw), dissertation. Leiden: Sidestone Press.

Wallet, B., 2007. Amsterdam: Ashkenazim until 1795, in: F. SkOlNIK \& M. Berenbaum (eds.), Encyclopedia Judaica (Second Edition), Vol. I, 106-107.

WoOdward, I., 2007. Understanding Material Culture. Thousand Oaks (CA): Sage Publications Inc. 
